\title{
Research Mentor: A Web-Based Resource Supporting Grantsmanship and Scientific Publication
}

\author{
Ingrid Glurich, PhD and Marie Fleisner
}

\author{
Keywords: \\ Grantsmanship \\ Information technology \\ Internet \\ Scientific publication \\ Corresponding Author: \\ Ingrid Glurich, PD, Director \\ Office of Scientific Writing and Publication \\ Marshfield Clinic Research Foundation \\ 1000 North Oak Avenue \\ Marshfield, WI 54449 \\ Tel: 7। 5-389-3072 \\ Fax: 715-389-5757 \\ Email: glurich.ingrid@mcrf.mfldclin.edu \\ Received: July 2, 2010 \\ Revised: September I, 2010 \\ Accepted: September 8, 2010 \\ doi: $10.3121 / \mathrm{cmr} .2010 .950$ \\ Disclosure: Presented in part at the \\ 15 th Annual HMO Research Network \\ Conference in Danville, PA, April 26-29. \\ 2009 (abstract published in Clinical \\ Medicine \& Research 2009;8:56); the \\ American Medical Informatics Association \\ Annual Symposium in Orlando, FL, May \\ 27-30, 2009; and the Association of Clinical \\ Research Professionals Global Conference \\ in Tampa, FL, April 23-27, 2010.
}

\begin{abstract}
A the largest physician-owned private multispecialty healthcare practice in central and northern Wisconsin and one of the largest in the nation, Marshfield Clinic has a long-standing track record in scientific research to support its healthcare mission. The Clinic's staff of 790 physicians serves over 40 regional centers in a largely rural setting in 80 clinical specialties and undertakes research in a broad range of disciplines. In addition, the Clinic's Research Foundation employs a staff of scientists who collaborate with clinician investigators. A rich research environment pervades the Marshfield system, supported by a state-ofthe-art informatics environment, access to an epidemiologically-defined study population for which detailed medical and demographic data are available, with its status as the largest population-based genetics repository in the USA. Not surprisingly, this rich research environment attracts researchers with a broad range of expertise and experience. An additional layer of complexity is added with multidisciplinary or multi-institutional research.
\end{abstract}

Preparing competitive scientific grant proposals responsive to emerging public health priorities is especially daunting for individuals collaborating on interdisciplinary and translational projects who lack experience and traditional training in grantsmanship. New page limits and a revision of the peer review process at the National Institutes of Health have created new challenges, even for seasoned investigators. To assist researchers in navigating the process of preparing successful grant proposals in an increasingly competitive research environment, a full-service research infrastructure was established over time at the Clinic's Research Foundation, including a Clinical Research Center, Epidemiological Study Center, Bioinformatics Research Center, Offices of Scientific Writing and Publication, Research Integrity and Protection, Sponsored Programs, and a Core Laboratory. However, coordinating assistance to busy clinicians proved challenging, and supplemental, conveniently-accessible resources were required by researchers for navigating the rich, but complex research environment.

To this end, Marshfield Clinic Research Foundation personnel teamed up to create a comprehensive informatics-based resource, Research Mentor, designed to support both new and established investigators in successful grant writing and manuscript preparation. The overarching purpose envisioned for Research Mentor was to serve as an educational resource on scientific writing related to research and as a bridge to internal resources, policies, and documents. The concept was to have scientific writing specialists centralize access to these 
Table 1. Research Mentor content and format evaluation.

\begin{tabular}{|c|c|}
\hline Statement & $\begin{array}{l}\text { Mean Score } \\
\text { (Range: 1-5) }\end{array}$ \\
\hline The title of the website provides information about its content. & 3.5 \\
\hline The 'Welcome' page makes clear the content/purpose of the site. & 3.6 \\
\hline The intended audience of the site is evident and clear. & 3.4 \\
\hline The information is clearly presented (i.e. reading level, technical level). & 3.9 \\
\hline The content is well-organized and clearly stated. & 3.5 \\
\hline The information presented is pertinent to your needs/purposes. & 4.4 \\
\hline It is possible to navigate the site without problem. & 3.5 \\
\hline The links are helpful and appropriate. & 4.1 \\
\hline The links are working (no dead ends or incorrect links). & 4.7 \\
\hline I would use and recommend this site as a research reference source. & 4.2 \\
\hline
\end{tabular}

resources to save investigators valuable time scouring the web in search of support tools. In addition, for internal personnel and investigators at institutions collaboratively working on research projects with Marshfield investigators, access to forms, policies, and support service personnel is also provided. Thus, Research Mentor was created as a web-based interactive resource that would provide direct links to other web-based educational resources which promote grantsmanship and scientific publication on the internet.

Institutional resources that support investigators and sponsored programs offices are not unique. As example, Duke University, ${ }^{1}$ Stanford University, ${ }^{2}$ and Virginia Polytechnic Institute and State University (Virginia Tech), ${ }^{3}$ all have websites for their Sponsored Programs/Research office that provide some online tutorials regarding grant writing, and Purdue's 'The $\mathrm{Owl}^{\prime 4}$ offers assistance with various aspects of manuscript development. However, we found none as comprehensive in their scope as Research Mentor, in providing support from research conceptualization, grant development, and submission to manuscript preparation within the context of the institutional research environment.

To facilitate access across its network of regional centers, Research Mentor was originally launched on Marshfield Clinic's intranet in 2008. Partially in response to requests for access from external collaborators who appreciated its value, and following exhibition of its contents and capabilities at several national conferences, Research Mentor was transferred to its current internet website at http://www.marshfieldclinic. org/mcrf/researchmentor in 2010, where it is a publically available resource. Access to research-related services and personnel, however, must remain limited to Marshfield Clinic investigators and their collaborators in the context of specific collaborative efforts, due to workload constraints on service personnel.

\section{Creation of Research Mentor}

Research Mentor was conceptualized and formatted to offer centralized access as an interactive website. Research Mentor was created and is maintained by Marshfield Clinic Research Foundation infrastructural support. Foremost, the website was designed to be user-friendly and interactive, allowing instant access to forms, policies, links, resources, and personnel. The goal was to develop a resource that would spare investigators frustrating and time-consuming searches of the Internet and various Clinic and Foundation websites. Facilitating navigation of clerical elements was particularly essential in providing assistance to individuals with little research experience or those who were newcomers to the Clinic environment.

To ensure compatibility with Marshfield Clinic's intranet website platform, Research Mentor was designed using the platform's designated template format. Research Mentor's content was initially created in Microsoft Word and then converted to XML language utilizing XML Copy Editor, a free software program released under the GNU public license. XML Copy Editor allows conversion of Microsoft Word documents into XML language using DTD/XML Schema/ RELAX NG validation, syntax highlighting, folding, tag completion, and tag locking. The content was then released to production using Marshfield Clinic's Content Director, an internally-developed application for managing web content. This application provides the capability to easily add, modify, release, and retire content.

Research Mentor applied a "planning to publication" approach to guide users to research fundamentals utilizing a logical flow which investigators navigate based on their level of familiarity with research and the local research environment. This design allows users to navigate in any sequence by choosing links within the text as well as links located at the top and bottom of each page.

Following completion of the prototype, the website was reviewed by the research services specialists and the Foundation's quality improvement team and adjusted based on recommendations. The final format was posted on the web for beta testing by 25 investigators randomly chosen from the Marshfield Clinic research database. Researchers were asked to explore the website and respond to a survey scrutinizing Research Mentor's content and format. The evaluation included 10 statements that respondents rated from 1 to 5 using Likert Scaling (table 1). A rating of 1 indicated "disagree completely" and 5 indicated "agree completely". The reviewers also were invited to submit comments to each 
question. Evaluation forms were received from 19 of the 25 testers $(76 \%$ return rate). Five respondents opted to return comments without completing the evaluation. Feedback was used to further modify the website's content.

\section{Response to Research Mentor}

To date, feedback on the website has been positive, especially from physicians who are new to the research environment. The "concept paper template" is an especially popular tool used by many investigators for outlining and planning their proposals. Support staff frequently refer researchers to the template because it effectively helps investigators focus and articulate their proposal design. Research Mentor additionally provides researchers with information and links to guide them in manuscript preparation, including how to write and submit a scientific manuscript. Investigators respond positively to the streamlined access to support staff and research-related forms which are cumbersome to find on the Intranet, as well as carefully compiled resources that enhance grantsmanship skills.

\section{Summary}

Applying informatics for creation of a comprehensive resource to support grantsmanship has offered time-economical solutions valued by new and established investigators and research support staff alike. Research Mentor has proven to be an important support venue for researchers attempting to procure grant funding. Since its launch on the internet, Research Mentor has also been accessed by researchers at collaborating institutions, including the University of Wisconsin-Madison. Public access has promoted crossinstitutional networking with appropriate and experienced personnel who can assist in developing competitive proposals and facilitate problem solving. Finally, posting the resource to the internet offers opportunities for keeping the website current through frequent updates and links to important new resources or changes in federal policies related to grant funding and research. In the increasingly competitive world of translational and cross-disciplinary research, Research Mentor offers a freely accessible competitive edge to all investigators who tap into this carefully-compiled, user friendly resource.

\section{References}

1. Duke University, Office of Sponsored Programs Website. Available at: http://finance.duke.edu/research/effort/faq.php. Accessed August 2, 2010.

2. Stanford University, Office of Research Administration Website. Available at: http://ora.stanford.edu/ora/ratd/nih_04.asp. Accessed August 2, 2010.

3. Virginia Tech, Office of Sponsored Programs Website. Available at: http://www.osp.vt.edu/. Accessed August 2, 2010.

4. The Purdue Online Writing Lab (OWL). Available at: http://owl. english.purdue.edu/. Accessed August 2, 2010.

\section{Author Affiliations}

Ingrid Glurich, PhD*; Marie Fleisner*

* Office of Scientific Writing and Publication, Marshfield Clinic Research Foundation, Marshfield, Wisconsin, USA 